\title{
Prediction Separation Performance of Teetered Bed Separation for Coarse Coal Slime
}

\author{
CHEN You Liang \\ School of Chemistry and Chemical Engineering,University of Science and Technology,Xi'an,China \\ youliangch@126.com
}

Keywords:TBS, coarse slime settlement, prediction model

Abstract. The paper focuses on separating the coarse slime for the particle size ranging from $0.3 \mathrm{~mm}$ to $2 \mathrm{~mm}$ in the teetered bed separator. The product yield and ash are researched as well as the partition ratio. The result shows that $\mathrm{R}-\mathrm{Z}$ model and Das model give prediction with worse precision , Asif model and Galvin model obtain better precision. When the teeter water velocity is quite low, Asif model get better result, and while the velocity is rather high, Galvin model is a better prediction model. The models are validated through the experimental data.

\section{Introduction}

The teetered bed separator is an highly efficient and widely used for coarse coal slime separation device, which is mainly discussed from four ways involving test research, mathematical model investigation, process improvement and flow field simulation ${ }^{[1,2]}$. The experimental study focuses primarily on exploring the appropriate operating parameters and structural design to increase separation precision for the equipment. Based on some empirical or semi-empirical formula and mechanism, relationship among various kinds of parameters are established in numerous models. Through improved process product quality and recovery could be enhanced greatly for coal slurry. The flow flied distribution characteristics, which is of the significance to carry out theoretical research, can be directly gained through numerical calculation or PIV testing techniques. Especially,the mathematical model researches mainly focus on the free settling laws of particles. The models which could predict the separation performance of the device could be used to not only indirectly guide on-sit operation but also directly support the selection of process equipment. Most models utilize different hindered-settling velocity formula and Reynolds number to predict equipment performance for teetered bed separator. Earlier proposed to use formula in the device is Galvin who notes that this formula can be used to assist the process design and predict the slip velocity of different size and density particles ${ }^{[3]}$. However, Gajanan et al discover that although at low teeter water rate between Galvin model's error and experiments' are less than 5\%, this model couldn't predict to it at high teeter water rate ${ }^{[4]}$.The purpose of the paper is to forecast the production yield and ash as well as separation density in order to evaluate prediction performance compared with experimental results.

\section{Experimental}

The samples from some coal preparation plant in Hebei province have the size ranging from 0.3 millimeter to 2 millimeter. The particle size analysis of coal feed is shown in Table 1 . The feed contains about $35.17 \%$ ash content in total. The data indicates that the feed is more evenly distributed for coarse particles and fines. Particle density characteristics at various size levels is shown in Fig.1. In order to validate the mathematical models which forecast the performance of the teetered bed separator, the experiments are carried out at different teeter water rates including $2.50 \mathrm{~cm} / \mathrm{s}, 3.31 \mathrm{~cm} / \mathrm{s}, 4.17 \mathrm{~cm} / \mathrm{s}$ and $5.00 \mathrm{~cm} / \mathrm{s}$. 


\begin{tabular}{|c|c|c|}
\hline Particle Size fraction & Yield(\%) & Ash(\%) \\
\hline $0.3-0.5 \mathrm{~mm}$ & 10.68 & 27.97 \\
\hline $0.5-0.8 \mathrm{~mm}$ & 27.1 & 33.27 \\
\hline $0.8-1.25 \mathrm{~mm}$ & 27.84 & 36.77 \\
\hline $1.25-2 \mathrm{~mm}$ & 34.38 & 38.67 \\
\hline $0.3-2 \mathrm{~mm}$ & 100 & 35.17 \\
\hline
\end{tabular}

Table 1 Size distribution of the feed

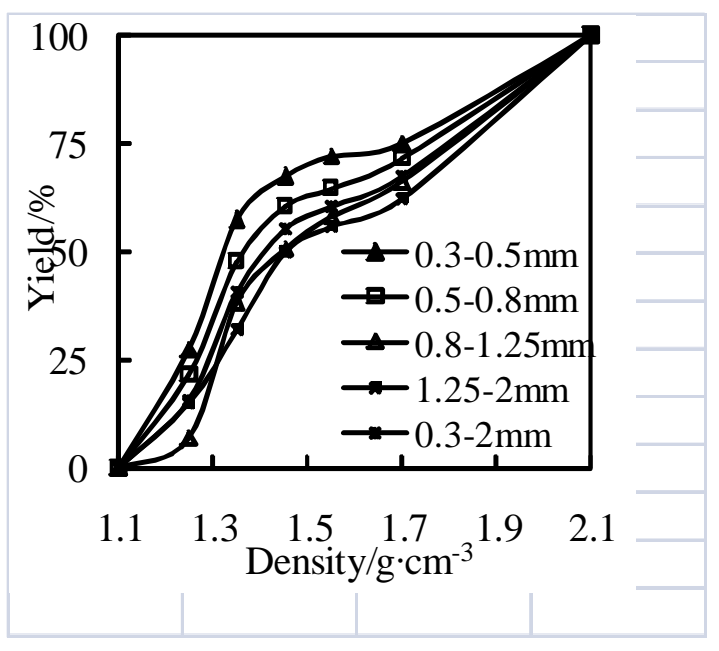

Fig.1 Particle density characteristics at various size levels

There are four mathematical models including R-Z model, Asif model, Galvin model and Das model ${ }^{[5-7]}$. The particle hindered-settling velocities in all of them are calculated by theoretical analysis, in order to predict the motion behavior of particle at different size and density distribution. Thus, the separation effect could be obtained for coarse coal slurry in the teetered bed separator. 
Table 2 The formula model

\begin{tabular}{ccc}
\hline Model & $n$ & $\operatorname{Re}$ \\
\hline R-Z model & $n=4.4 * \operatorname{Re}^{-0.1}$ & $\operatorname{Re}=\left[\frac{4 \rho\left(\rho_{s}-\rho\right) d^{3} g}{55.5 \mu^{2}}\right]^{5 / 7}$ \\
\hline Asif model & $\frac{4.8-n}{n-2.4}=0.043 G a^{0.57}$ & $\operatorname{Re}=\left(2.33 G a^{0.018}-1.53 G a^{-0.016}\right)^{13.3}$ \\
\hline Galvin model & $n=\frac{5.1+0.27 \mathrm{Re}^{0.9}}{1+0.1 \mathrm{Re}^{0.9}}$ & $\operatorname{Re}=\left[\left(14.5+\left(g\left(\rho_{s}-\rho\right) \rho\right)^{0.5} 1.83 d^{1.5} / \mu\right)^{0.5}-3.81\right]^{2}$ \\
\hline Das model & $n=\frac{2\left(2.35+0.175 \operatorname{Re}^{0.75}\right)}{1.0+0.175 \operatorname{Re}^{0.75}}$ & $\begin{array}{l}\log _{10} \operatorname{Re}=P(A)+\log _{10} R(A) \\
P(A)=[(0.0017795 A-0.0573) A+1.0315] A-1.26222 \\
R(A)=0.99947+0.01853 \sin (1.848 A-3.14) \\
A=\log _{10} A r\end{array}$ \\
\hline
\end{tabular}

\section{Results and Discussion}

Product yield and ash. The experimental clean product and the predicted data are shown Fig.2(a). It is notable that with the teeter water risen an increase of the coal fines yields in the four forecasting models is roughly consistent with the trend of trial values. A close inspection of these curves reveals that this counter current plays an important role in the teetered bed separator. Both Asif model and Galvin one are superior to Das or R-Z one. At low teeter water velocity the calculation result from Galvin model is the best given the most favorable data.Fig.2(b) shows the results of fines coal ash compared that from tests with that from four models while the teeter currents vary. The data show that the product ashes are roughly raised with the help of the gradually increased counter currents. The test results are analyzed to understand the phenomenon of the particle mismatch mostly caused at the teeter water rate between $3.33 \mathrm{~cm} / \mathrm{s}$ and $4.17 \mathrm{~cm} / \mathrm{s}$, as is similar to the result from models except R-Z model. The forecast outcome of R-Z model fluctuates according to the water flow and also it does not meet the actual and objective requirements. In Fig.2(b) it appears that there is a big gap among all curves, resulting from the similar motion behaviors between particles with high density and low size and ones with low density and high size.
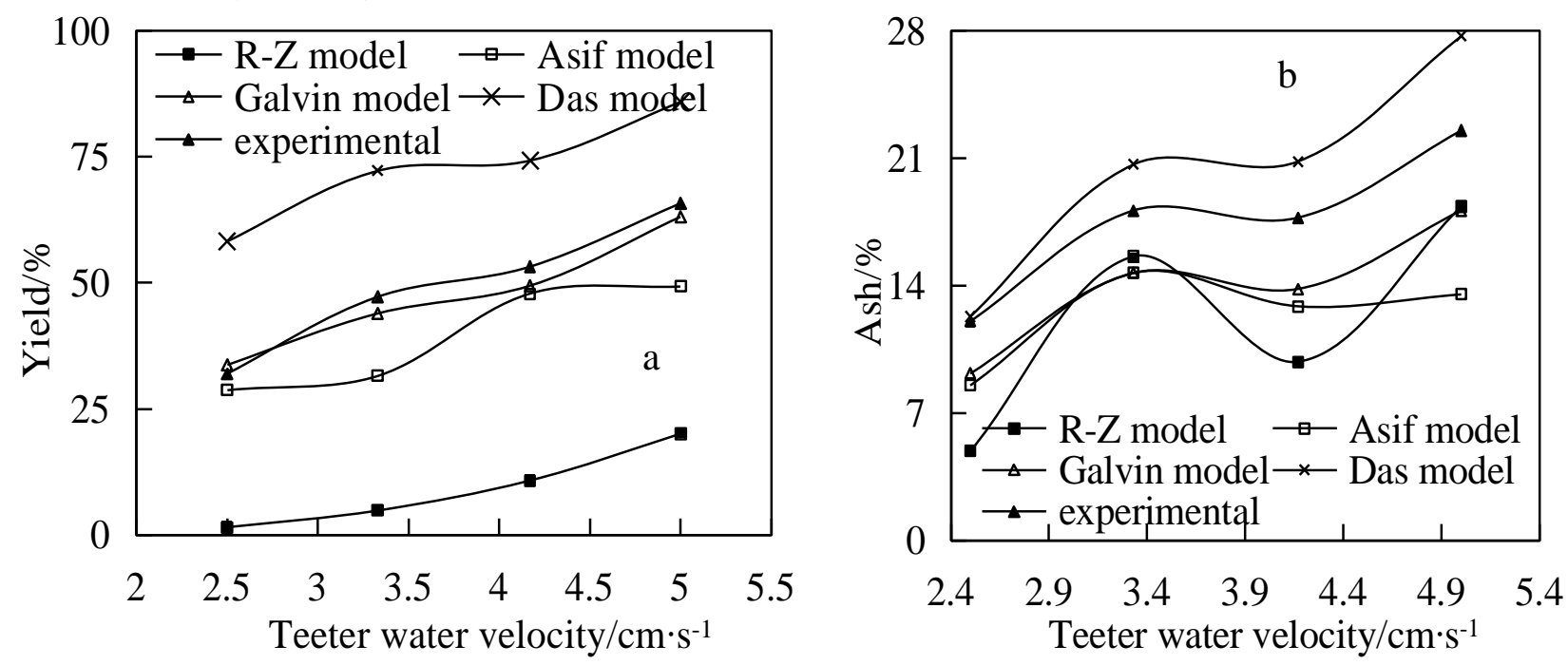

Fig.2 Comparison of predicted and experimental results 
Ecomparison. The results of the comparison between experiment and predicted distribution curves when the teeter water rate is held constant $(2.5 \mathrm{~cm} / \mathrm{s}, 3.33 \mathrm{~cm} / \mathrm{s}, 4.14 \mathrm{~cm} / \mathrm{s}$ and $5.00 \mathrm{~cm} / \mathrm{s}$ respectively) are presented in Fig.3. It appears that the optimal simulation model is Galvin model which obtains the best consistency with tests no matter how much the flow rate is. The predicted accuracy of Asif model can also be acceptable at the low counter currents, while at high teeter water rate this model fails to be used for forecasting the distribution curves of coal slurry. The other two models are difficult to describe the actual situation.

Comparison of prediction models. By comparing with the results of all models, the prediction accuracy of both R-Z model and Das model are inferior to other two models. The product yields and distribution rates can be achieved by Galvin model and Asif model in which there is a big deviation of product ash. This could be attributed mainly due to ultrafine coal slime and particle misplacement without giving any consideration. These two models also need to be further optimized.
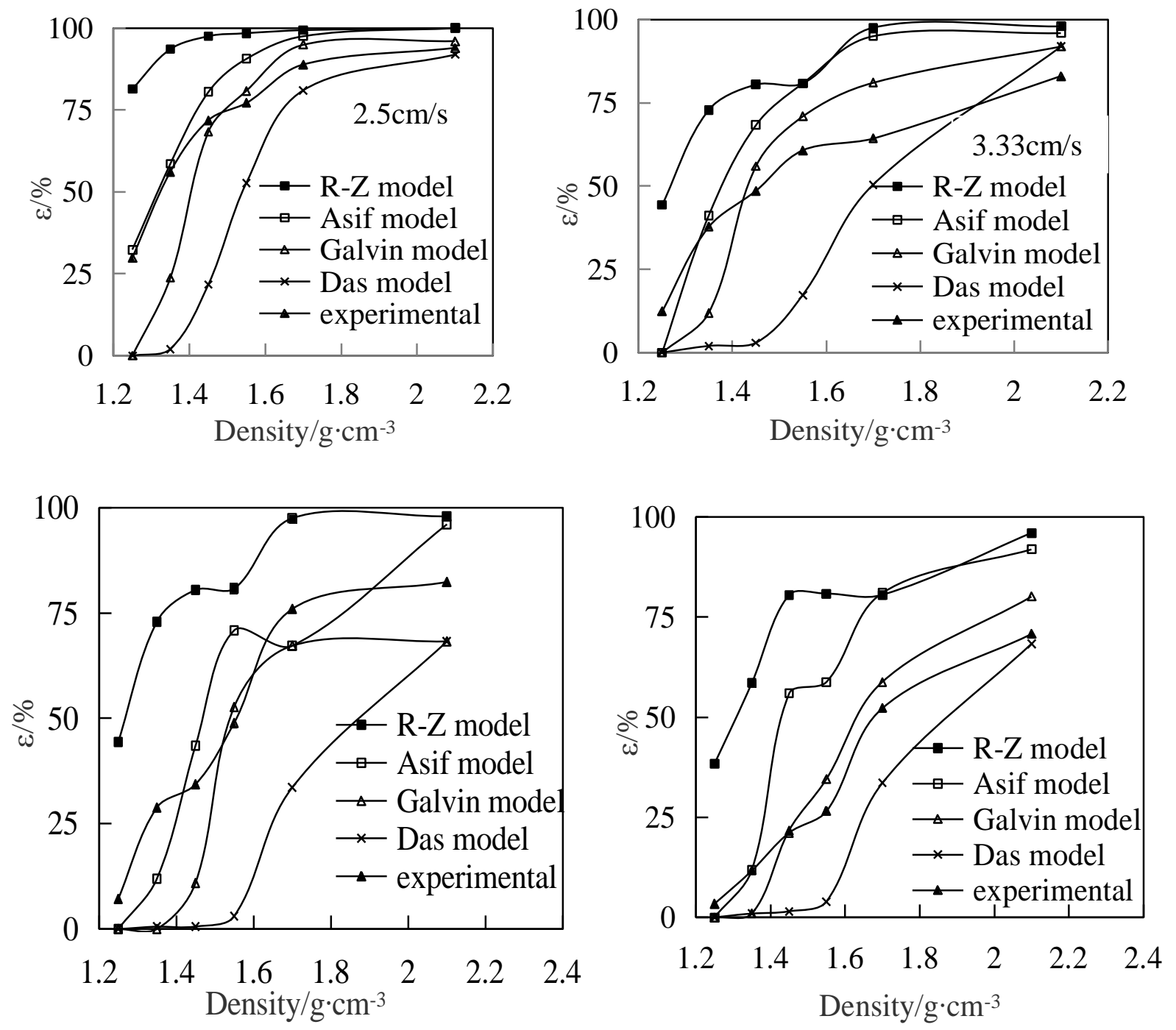

(c) $4.17 \mathrm{~cm} / \mathrm{s}$

(d) $5.00 \mathrm{~cm} / \mathrm{s}$

Fig. 3 Comparison of predicted distribution rate and experimental result with teeter water velocity

\section{Conclusions}

Predicting the performance of the teeter bed separator for coarse coal slime could provide reliable,fast,scientific and theoretical basis for production operations and equipment selection. Compared with experimental results, Galvin model and Asif model have higher accuracy and the significance of practical application. These mathematical models needed to improve could further coarse slurry separation theory of the teeter bed separator. 


\section{References}

[1] Y. Lu, J. T. Chen, L. Zhang, et al. Research progress and development tendency of the teetered bed separator. Mining \& processing equipment. Vol. 43(2015), p.9-11

[2] Y. L. Chen, W.L. Liu, K. F. Ma, et al. Numerical Simulation of the Flow Field in the Teetered Bed Separator. Journal of China University of Mining \& Technology. Vol.40(2011), p.608-611

[3]K. P. Galvin, S. J. Pratten, G. Nguyentranlam. A generalized empirical description for particle slip velocities in liquid fluidized beds. Chem. Eng. Sci. Vol.54(1999b), p.1045-1052

[4] Gajanan Kapure, Chandrakala Kari, S. Mohan Rao, et al. The feasibility of a slip velocity model for predicting the enrichment of chromite in a Floatex density separator. Int. J. Miner. Process. Vol.82(2007), p.86-95

[5] L. Yang, J. T. Chen, L. Zhang. Reseach on feed range of teetered bed separator and simulation. Coal Technology. Vol.33(2014), p.329-331

[6] B. Sarkar, A Das. A comparative study of slip velocity models for the prediction of performance of floatex density separator. International Journal of Mineral Processing. Vol.94(2010), p.20-27

[7] M. Asif, N. Kalogerakis, L. A. Behie.Hydrodynamics of liquid fluidized beds including the distributor region. Chemical Engineering Science. Vol.47(1992), p.4155-4166 